\title{
The role of risk perception in making flood risk management more effective
}

\author{
M. Buchecker ${ }^{1}$, G. Salvini ${ }^{2}$, G. Di Baldassarre ${ }^{3}$, E. Semenzin ${ }^{2}$, E. Maidl ${ }^{1}$, and A. Marcomini ${ }^{2}$ \\ ${ }^{1}$ Swiss Federal Research Institute WSL, Unit Economy and Social Sciences, Birmensdorf, Switzerland \\ ${ }^{2}$ Informatics and Statistics, Ca' Foscari University of Venice, Venice, Italy \\ ${ }^{3}$ UNESCO-IHE Institute for Water Education, Delft, the Netherlands
}

Correspondence to: A. Marcomini (marcom@unive.it)

Received: 4 April 2012 - Published in Nat. Hazards Earth Syst. Sci. Discuss.: -

Revised: 14 August 2013 - Accepted: 15 October 2013 - Published: 27 November 2013

\begin{abstract}
Over the last few decades, Europe has suffered from a number of severe flood events and, as a result, there has been a growing interest in probing alternative approaches to managing flood risk via prevention measures. A literature review reveals that, although in the last decades risk evaluation has been recognized as key element of risk management, and risk assessment methodologies (including risk analysis and evaluation) have been improved by including social, economic, cultural, historical and political conditions, the theoretical schemes are not yet applied in practice. One main reason for this shortcoming is that risk perception literature is mainly of universal and theoretical nature and cannot provide the necessary details to implement a comprehensive risk evaluation. This paper therefore aims to explore a procedure that allows the inclusion of stakeholders' perceptions of prevention measures in risk assessment. It proposes to adopt methods of risk communication (both one-way and two-way communication) in risk assessment with the final aim of making flood risk management more effective. The proposed procedure not only focuses on the effect of discursive risk communication on risk perception, and on achieving a shared assessment of the prevention alternatives, but also considers the effects of the communication process on perceived uncertainties, accepted risk levels, and trust in the managing institutions.

The effectiveness of this combined procedure has been studied and illustrated using the example of the participatory flood prevention assessment process on the Sihl River in Zurich, Switzerland. The main findings of the case study suggest that the proposed procedure performed well, but that it needs some adaptations for it to be applicable in different contexts and to allow a (semi-) quantitative estimation of risk perception to be used as an indicator of adaptive capacity.
\end{abstract}

\section{Introduction}

Since the earliest recorded civilisations, such as those in Mesopotamia and Egypt that developed in the fertile riparian areas of the Tigris, Euphrates and Nile rivers, humans have tended to settle on floodplains because they offer favourable conditions for economic development (Vis et al., 2003; Di Baldassarre et al., 2010). It is estimated that almost one billion people: the majority of them the world's poorest inhabitants, currently live in flood-prone areas (UNESCO, 2004). As a result, flooding causes about half of all deaths from climate-related disasters (Ohl and Tapsell, 2000). Moreover, economic damages and fatalities caused by floods are increasing in many parts of the world: largely due to continuous population growth along floodplains, changes in land use, and changes in climate, with specific concern relating to sea level rise (Milly et al., 2002; Di Baldassarre et al., 2010).

As a result, the number of proposed risk-based methodologies addressing this issue has increased in the last decades (Cirella et al., 2013) and have been improved by including the relationships between risk analysis, risk evaluation, and risk management (BUWAL, 1999; Hollenstein, 1997; Kienholz, 1998). In this context, risk analysis consists of the identification of danger, the analysis of relevant processes, and the estimation of potential damage or loss and its consequences (Kienholz, 1994). Risk evaluation is a "qualitative or quantitative characterization of damage with regard to its likelihood and extent" (as translated from Hollenstein, 1997) and in terms of its acceptability (Analysis, 2005), and its results must be seen in the context of social, economic, cultural, historical and political conditions. Risk management comprises all the preventive measures for reducing, controlling and regulating natural risks (Blöchl and Braun, 2005). 
In the existing risk assessment (i.e. risk analysis and evaluation) and management approaches, the most widely used calculation to express risk is a function of hazard, vulnerability and exposure (Crichton, 1999). Usually, however, experts have become specialised on technical aspects (e.g. hydrological modelling for hazard assessment), while there are few experts who adopt comprehensive approaches that integrate environmental, social and economic perspectives (Cirella et al., 2013). Moreover, most approaches have a strongly theoretical background and are rarely applied in practice (Blöchl and Braun, 2005). Although some innovative risk-based approaches that integrate risk evaluation and management exist (e.g. Ashley and Blanksby, 2007), the most widely applied is the traditional approach: referred to as flood defence, in which a number of serious limitations exist (Merz et al., 2010). For instance, the practice of raising the heights of river levees, dikes or embankments has increased during the last two centuries and rivers have become increasingly controlled, which has reduced the probability of flooding in many regions. However, the downside to raising such barriers to protect flood-prone areas is that damage is often increased if failure occurs (Vis et al., 2003) because of increased development in areas that are perceived to be safe. The so-called "levee effect" is the perception by floodplain inhabitants that all flood risks have been eliminated once the barrier-like levee is raised (Burton and Cutter, 2008). Given that risk can be defined as a combination of the probability of flooding and its potential adverse consequences (Helm, 1996), raising the levee systems reduces the flooding probability, but the potential adverse consequences (flood damage) might significantly increase. This clearly indicates that, by including proper socio-economic considerations within the flood assessment process, one might end up with the paradox that flood risk actually increases as a result of strengthening flood defence structures. Ludy and Kondolf (2012) exemplified this discrepancy when they surveyed Californian residents who were living in areas behind levees that were certified as being protected up to a 100 -yr flood event, in order to assess their awareness of the risk of flooding. The survey indicated that these residents were not aware of the residual risk of being flooded, and thus perceived themselves to be safe, despite their relatively high level of education (Ludy and Kondolf, 2011).

Hence, it is reasonable that flood risk assessment should not merely be a scientific activity but a socio- and economicoriented approach that takes the social dimension of flood risk (Schmidt-Thomé et al., 2006), and, in particular, the stakeholders' risk perception, into account (Plattner et al., 2006a). Here, we do not understand risk perception in a narrow sense as the "intuitive judgement of individuals and groups of risks" (Slovic, 2000), but in a wider sense as the perception of the risk problem, including its causes, the possible mitigation strategies of the risk, and the related consequences (e.g. Jurt Vicuña Muñoz, 2009; Lane et al., 2011).
A literature review on state-of-the-art methods for evaluating risk perception highlighted that the existing risk perception approaches have a strong theoretical nature, that very few exceptions are available that are aimed at forecasting stakeholders' risk assessment (e.g. Plattner et al., 2006b), and that these focus on the perception of risks rather than the perception of risk prevention measures. From this review, we concluded that a new procedure to (semi-) quantitatively include stakeholders' perception of risk prevention measures into a risk assessment methodology based on risk communication is needed so that the gap between theory and practice in flood risk management can be bridged. It is based on coupling two possible ways of communicating with stakeholders: interviews or surveys, and participation. Both have their strengths and weaknesses (Fiorino, 1990; Buchecker et al., 2010; Parkins, 2010), but we argue that combining the two allows the reduction of biases in the assessment.

This procedure was developed in the frame of the EU FP7 project KULTURisk (Knowledge-based approach to develop a culture of risk prevention) with the aim of integrating stakeholders' risk perception into a risk-based methodology that evaluates the benefits of prevention measures for water related disasters. In this context, risk prevention is defined as the objective of reducing risk to an acceptable level by lessening the potential adverse impacts of natural hazards through actions taken in advance. Thus, risk prevention measures include all the initiatives (i.e. early warning systems, structural and non-structural measures) taken before the occurrence of natural disasters that aim to avoid the unacceptable risk.

A conceptual framework and a risk-based methodology to address water related hazards by integrating environmental, social and economic components are currently under development within KULTURisk. Their structure foresees the risk perception component under a paradigm of adaptive capacity, in which society adapts to the changing environment by earning and storing knowledge and experience (Berkes et al., 2003).

This paper focuses on presenting the procedure for including the evaluation of stakeholders' perception of prevention measures against natural hazards within the risk assessment methodology, to create a tool that enables implementation of the comprehensive risk assessment approaches in practice.

Accordingly, a state of the art review of the existing approaches of evaluating risk perception and its dimensions is presented in Sect. 2. Based on the results of the review, a proposal of how to evaluate stakeholders' risk perception of water related hazards has been formulated and presented in Sect. 3. An illustrative example of the proposed risk communication procedure, through a participatory flood prevention assessment process in the Sihl River within the Zurich (Switzerland) area, is described in Sects. 4 and 5. Finally, conclusions are drawn and future developments are highlighted in Sect. 6. 


\section{Methods and approaches to evaluate risk perception and its dimensions}

\subsection{Including risk perception in risk evaluation and risk management}

The importance of developing a procedure to integrate risk perception into risk assessment for an effective and socially accepted risk management application is clearly evident (Renn, 1998; Pidgeon, 1998).

The first authors to realize the importance of including the human component in natural hazards research date back to the 1940s (White, 1945). In the following decades, geographical natural hazards research described natural hazards as extreme events that produce negative effects when interacting with social systems (Parker and Harding, 1979). Geographical natural hazard research defines risk as the product of external risk (hazard), social vulnerability and resilience (Birkmann et al., 2013), which underlines the notion that natural hazards cannot exist without some form of human adjustment to them.

In the last decades, the methodology for the analysis and evaluation of natural risks has been improved by including the relationships between risk analysis, risk evaluation and risk management (BUWAL, 1999; Hollenstein, 1997; Kienholz, 1998). Further improvement has been achieved by referring to more comprehensive frameworks, such as the PLANAT (Swiss National Platform for Natural Hazards) risk management cycle (see www.planat.ch), which is composed of five elements: risk identification, risk analysis, risk appraisal, risk reduction and management of residual risks (Merz and Emmermann, 2006; Petrow et al., 2006). Most approaches have a strongly theoretical background but practical applications are needed (Blöchl and Braun, 2005). Höppner et al. (2012) pointed out that, although both improved risk communication and the building of social capacities have been advocated as vital ways to increase societies' resilience towards natural hazards, a gap exists between theory and practice. Although some innovative risk assessment methodologies (that include risk analysis and evaluation) exist (e.g. Merz et al., 2010), they are rarely applied in risk management practice (Höppner et al., 2012).

As a consequence, the most widely applied management strategy is the traditional flood defense approach ("fighting floods"), which, according to current European strategies, is to be replaced by the integrated flood management ("living with floods") strategy (Merz et al., 2010), which aims at minimizing the human, economic and ecological losses from extreme floods while maximizing the social, economic and ecological benefits of ordinary floods (Di Baldassarre and Uhlenbrook, 2012).

To bridge the gap between theory and practice in risk assessment and management, accepted non-structural prevention measures need to be considered and introduced, which in turn requires integration of stakeholders' perception of these measures into the risk assessment. Before suggesting a procedure to achieve this requirement, we will briefly review the literature to consider the potential of existing approaches to quantifying the perception and acceptance of prevention measures.

\subsection{Approaches for risk perception evaluation}

According to the 1992 UK Royal Society report on "Risk: Analysis, Perception and Management", risk perception includes "people's beliefs, attitudes, judgments and feelings, as well as the wider cultural and social dispositions they adopt towards threats to things that we value" (Pidgeon et al., 1992). This social science definition can be broadened, since it is a wide range of characteristics of hazards (such as perceived causes of the risk and consequences of mitigation measures for people's livelihood) rather than just an abstract expression of uncertainty and loss, that people appear to be concerned with when forming perceptions (Pidgeon, 1998). Recent research indicates that the perceived benefits of mitigation measures also need to be considered in risk perception research (Bubeck et al., 2012).

In the scientific literature, risk perception research has investigated a wide range of hazardous events that mainly consist of technical (e.g. nuclear power plants), environmental (e.g. air pollution) and natural (e.g. floods, landslides and earthquake) hazards (Ho et al., 2008). We have analyzed the state of research based on keyword searches in databases of ISI-articles (Web of Science) and books (e.g. NEBIS).

Until recently, risk perception research has been dominated by two fundamentally diverging approaches: the psychometric approach that is based on a positivist research tradition, and the cultural theory approach that considers risk as a societal construction (Pidgeon, 1998; Sjöberg, 2000; Tansey, 2004). In the last decade, the somewhat intermediary concept of the mental model has increasingly been used to understand lay people's conceptions of risk problems and as a basis to inform risk communication (Morgan et al., 2001).

The psychometric approach was launched in 1978 by Fischoff et al. (1978). The empirical work reported in that paper was then extended in several other studies (Rohrmann, 1995). Psychometric work on risk perception utilizes the methodologies of attitude research: typically to elicit people's expressed risk evaluation and preferences for a range of hazards (Pidgeon, 1998). The findings show that people's judgements of risk and its acceptability are related systematically to qualitative characteristics of hazards, such as their judged controllability, voluntariness, dread, degree of organized safety, catastrophic potential, equity, and familiarity (Fischoff et al., 1978). These factors can be classified into two main groups: the first is the "dread" of the risk (how uncontrollable, catastrophic, dangerous and involuntary) and the second is the "knowledge" of the risk (how chronic, unknown, delayed, and new) that the exposed people have. Therefore, as Slovic (1999) argued, risk assessment is 
actually subjective and represents a blending of science and personal judgment based on important psychological, social, cultural, and political factors. These factors not only influence the risk perception of laypersons, but also of "experts", whose judgements of risk are based on models and formulas, but are also influenced by emotions (Slovic, 1999). One of the main outcomes of psychometric studies (e.g. Griesmeyer, 1982; Geiger, 1993; Marris et al., 1997; Jasanoff, 1998; Belzer, 2001; Skjong and Wentworth, 2001; Siegrist et al., 2006) was the identification of a marked difference in risk perception not only between "experts" and "laypersons" but also of a strong inter-individual variation. This difference is said to be related to the various kind of dimensions used in risk evaluation and to the priorities that are associated with these dimensions.

In contrast to these universal and individual-focused findings based on the psychometric approach, other research has been based on more constructivist approaches (Vlek and Stallen, 1980, 1981; Otway and von Winterfeldt, 1982) and provides some indication that risk perception is affected not only by the damage (e.g. the estimation of numbers of fatalities), but also by qualitative understandings or meanings associated with hazards. These understandings are correlated within the specific context, determined by its values, politics and culture (Wildavsky and Dake, 1990; Dake, 1991; Douglas, 1992). Specifically, the cultural theory approach, which was mainly adopted in anthropology, examines cultural categories that act as basis for the individuals' construction of risks as a means of maintaining cultural borders (Jurt Vicuña Muñoz, 2009). According to this approach, risk perception was linked to stakeholders' relationship with responsible institutions rather than to physical processes.

More recently, the concept of the mental model has been adopted in risk perception studies. This concept is based on the assumption that individuals construct and further develop their model of reality based on direct experience and available information (von Glasersfeld, 1993; Biggs et al., 2011), by changing the existing model in their mind or by rejecting the information. Accordingly, individual cognitions of environmental systems can differ considerably: even under conditions of similar availability of information, as confirmed by a number of empirical studies on mental models of technical risks (Cousin and Siegrist, 2010) and environmental risks (Leighton and Bisanz, 2003).

In the last years, several studies have investigated risk perception using more constructivist concepts of the mental model (Natan, 2008). Kolkman et al. (2007) suggested that people's (laypeople as well as experts) mental models of risks are shaped on the one hand by information available to them and on the other hand by their position, that is the result of their personal, social or institutional background. According to this approach, risk perception is considerably shaped by interests of stakeholder groups.

The relevance of group characteristics is also emphasized by research on individual risk behavior. According to the influential Protection Motivation Theory, formulated by Rogers (1975), individual behavior of taking precautions depends on the one hand on the perceived severity of a threatening event and the efficacy of the recommended preventive behavior, and on the other hand on the socially distinctive factors of the perceived vulnerability and the perceived selfefficacy.

Research based on communication theory furthermore highlights the significant impact on risk perception by the media. The complex messages of the media about risks and hazards are expected to influence the attitudes of public opinion and to amplify some risks and attenuate others (Kasperson, 1988; Rohrmann, 1999). Further research by Boholm (1998) and Lévy-Leboyer et al. (1996) indicates that the influence of the media differs considerably among nations: this variation varies from the type of information as well as the manner in which news is presented and evaluated.

Summarizing the findings of this review on risk perception literature, we have discovered a high variety of approaches of conceiving risk perception and a wide range of potential influence factors. Most of the literature is, however, of either theoretical or universal nature and does not provide clear indications as to how to quantify risk perception or, more precisely, on the perception of prevention measures. In this context two exceptions can be mentioned that offer the potential to forecast stakeholders' risk assessment: the Modern Portfolio Theory (MPT) and the research carried out by Plattner et al. (2006b) on Perception Affecting Factors. These approaches will be briefly described in the following paragraphs.

\subsubsection{Modern Portfolio Theory (MTP)}

MPT is a notion developed in the 1950s through to the early 1970s by Harry Markowitz (Elton and Grumer, 1997). In light of this theory, individuals make decisions about a particular portfolio (defined as a combination of assets), based on the expected levels of risk and benefits, and investigate tradeoffs between risks and expected return of investment. In general, MPT asserts that assets with higher expected returns are riskier. It explains how to select a portfolio with the highest expected return for a given amount of risk, or the lowest risk for a given expected return, and to select a portfolio with the lowest possible risk by carefully choosing the proportions of various assets. MPT describes how to find the best possible diversification strategy, based on different types of assets. A collection of different assets can for example have lower overall risk than the sum of the individual risks. Following this theory, an individual tends to choose to take a higher risk if the reward is higher. In this context, risk perception determines whether the individuals are "risk adverse" or "risk takers". It therefore determines the preferences of a scenario in which risk is minimized resulting in a lower benefit versus a scenario in which risks are higher leading to a higher benefit. 
From the literature review, we found a promising attempt to implement MPT in the context of natural hazards. The first application of MPT to flood risk management was conducted by Aerts et al. (2008) and explored how MPT can contribute to operationalizing the concept of adaptive water management for developing flood management strategies in the Netherlands. Specifically, the paper presents a numerical example of how to develop portfolios of flood management activities that generates the highest return under an acceptable risk for an area in the central part of the Netherlands. In this example, the investment costs of the different assets are neglected, and the authors suggest that the application of MPT to cost-benefit analysis for flood management would involve a straightforward computation of expected social surplus over the sets of flood management alternatives. The authors conclude that, with many assumptions, it can be stated that MPT encourages a systematic discussion of the relationship between the return and risk of individual activities and the return and risk of complete portfolios. Therefore, MPT could be a valuable tool for learning and re-evaluating portfolios once more information about flooding and their probabilities becomes available. Therefore, this work seems to offer a promising development in terms of identifying optimal and, if considered on the level of stakeholder groups, also best accepted risk prevention strategies in the near future. However, since it is beyond the scope of this paper to develop an economic analysis of flood impacts (this task is currently under development in KULTURisk), the procedure presented in Sect. 3 will not make use of Modern Portfolio or Modern Disaster Theories.

\subsubsection{Plattner's Perception Affecting Factors (PAF)}

The research carried out by Plattner et al. (2006b) aimed at quantifying risk perception based on an expressed preferences approach (e.g. Fischhoff et al., 1978). The objective of this work was to propose a methodology to quantify individual risk perception and evaluation. The proposed model integrates the effective individual risk and a weighted mean of relevant Perception Affecting Factors (PAF). This study is based on the hypothesis that different individuals and social groups (distinguished according to shared values, beliefs and educational background) attribute different weights to different PAF. Hence, following Plattner and colleagues, the perceived risk can be quantified as being a function of the effective individual risk, PAF, and the corresponding calculated weights. The selection of the relevant PAF was carried out through an analysis of the psychometric risk perception literature and the compiled list of mentioned risk dimensions. Examples of these dimensions are: the perceived likelihood of dying from the hazard; the perceived degree of scientific knowledge about the risk; knowledge of the risk by those exposed; emotion of fear evoked by the risk; the possibilities of influencing the risk; the perceived recurrence frequency; the predictability of the event; the expected future increase or decrease of the risk in terms of event frequency; and the intensity of impacts on society. From this list, the most relevant risk dimensions were selected via a Delphi method. The resulting short list was compared with the findings from the recent literature and, in a final step, discussed in a workshop with eighteen risk perception experts. Moreover, in order to quantify the weighting of the PAF representing their specific impact, an Analytical Hierarchical Process (AHP, Saaty, 2001) was conducted during that workhop. This list of PAF and their weight was tested through a plausibility check, by applying them to a constructed case study. Finally, the methodology was validated based on empirical data of a survey that recorded the populations' risk perception in six regions in Germany (Plapp, 2004). The respondents were asked to judge each of three hazards: storm, flood and earthquake, regarding their individual perceived risk and regarding nine risk dimensions that were based on (mainly psychometric) research literature (e.g. Brun, 1992; Karger and Wiedemann, 1998). The analysis confirmed a realistic selection by experts of the PAF and plausible orders of magnitude for calculated perceived risk.

With his research approach, Plattner managed to integrate qualitative and quantitative assessments. Once the aspects have been determined, the assigned numerical values, with their associated weights, are formulated. This analysis allows not only a ranking of the PAF, but also an assessment of their magnitude that should be taken into consideration in decision-making processes.

Both MPT and PAF approaches allow for a forecast of stakeholders' risk assessment, but they are both highly individualistic and non-contextual since they do not consider the socio-cultural context of risk perception. Furthermore, they focus too narrowly on risk awareness rather than on the perception of risk prevention strategies. Bubeck et al. (2012) have, however, demonstrated that stakeholders' risk awareness was only weakly related to their attitude towards prevention measures. Moreover, Jurt Vicuña Muñoz (2009) has shown that stakeholders perceive and assess risks mainly in terms of their consequences for their livelihoods, and these consequences are predominantly related to the prevention measures rather than to the risks. Only first explorative studies, however, have so far examined stakeholders' perceptions of risk prevention measures. This risk aspect is always related to the social and economic context and thus cannot be answered with "laboratory research". Accordingly, in order to incorporate the social aspects of the context into risk assessment, the inclusion of risk communication (both one-way, such as local surveys or interviews, and two-way communication) seems to be a promising option (American Society of Civil Engineers, 2007; Höppner et al., 2012). Both approaches have been tested in the first studies on the perception of risk prevention measures, with some recording individual and group perceptions (e.g. Jurt Vicuña Muñoz, 2009, Bowman and White, 2012), whereas others focused on the change of stakeholders' perceptions through participatory 
Table 1. Pros and cons of risk communication approaches.

CONSULTATION PROCESS (INTERVIEWS, SURVEYS)

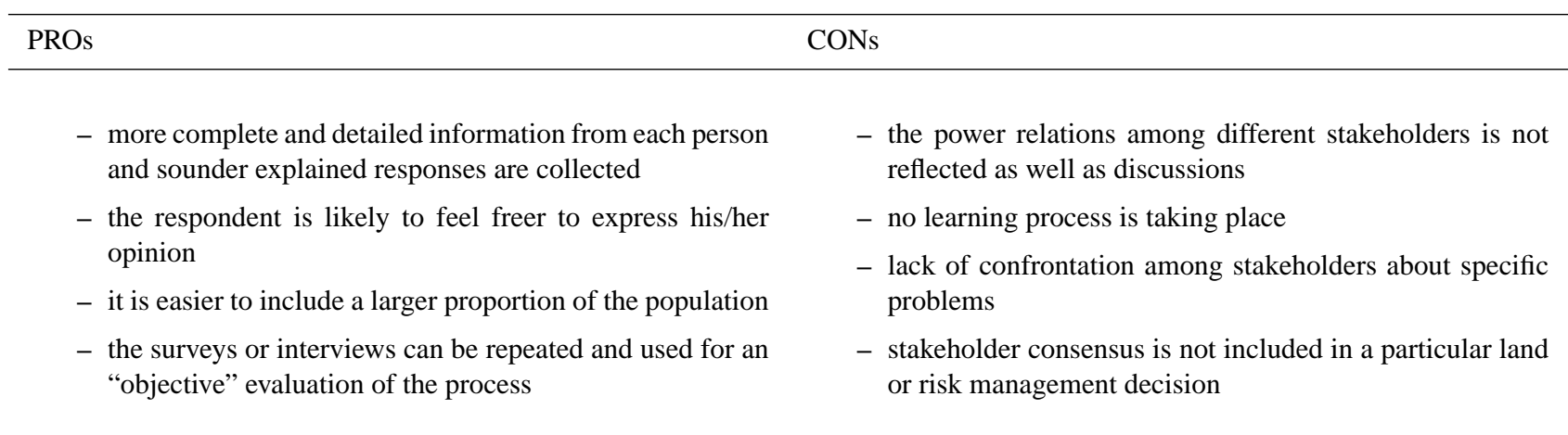

PARTICIPATORY INVOLVEMENT PROCESSES

PROs

- social interaction encourages the achievement of stakeholder consensus in a risk management decision

- higher level of stakeholder engagement, by giving participants the opportunity to communicate their views and judgments to the other participants as well as learn from them

- participants can approach the problem in a more integrated way by encouraging exchange of positions and considering issues in relation to the common good rather than individual interest

- opportunity to follow up with group dynamics in which evolving discusses play a key role

- participants can be challenged by others more profoundly than in semi-structured interviews

- local stakeholders are empowered in land and risk decisions

- stakeholders are actively involved, working hand-in-hand with land use planners and policy makers

- realistic expectations are created via a networking of building trust and enhancing commitment

- facilitates the satisfaction of their needs and acceptance of decision-based planning

- researchers and planners access to local expertise and knowledge
- tendency to avoid conflicts

- it is difficult to engage stakeholders in active participation

- the number of participants is limited processes (Howgate and Kenyon, 2009; Posthumus et al., 2008), while both mainly used qualitative methods. In the following paragraph the importance, and the potential role of risk communication in risk management will be briefly described, while in Sect. 3, the KULTURisk proposal on how to capture risk perception through risk communication approaches to make flood risk management more effective, will be presented.

\subsection{Risk communication approaches}

Risk communication is becoming an increasingly important activity in response to the changing nature of risk governance because it must serve multiple purposes and functions: from the framing or assessment of the risk situation to the implementation and evaluation of measures (Renn, 2005; Höppner et al., 2012). Furthermore, risk communication is moving 
beyond the one-way provision of information and the building of trust in risk-managing bodies towards a two-way exchange of knowledge and views with stakeholders (Höppner et al., 2012). In the sociological, normative, and management literature, the importance of stakeholder involvement has been widely discussed: both in a general framework (Stirling, 2005; Blok, 2007) and in particular within the context of risk management. In the latter case, stakeholders' participation has been considered to be an essential aspect to be included in the institutional and normative processes linked with risk management (Felt and Wynne, 2007). It takes into account the relationship between engagement, trust and riskbased decision-making (Petts, 2008), and explores how to improve the dialogue between science and policy (Wynne, 2006). These aspects emerge from the EU Floods Directive (EC, 2007) to enhance local preparedness, and highlight the importance of applying an integrated risk management approach when implementing flood management plans while taking stakeholder views and preferences into account.

Two strategies exist for accessing stakeholder perceptions of risk: by consulting individual stakeholders via questionnaires, surveys or interviews (one-way communication), and by involving the stakeholders directly in the risk assessment process, which is often via group-selected assessment (two-way dialogue) (Höppner et al., 2012). These two approaches differ in several aspects and reflect different levels of stakeholder participation and empowerment of stakeholders within the decision-making process. As described in Table 1, both have advantages and limitations (Fiorino, 1990; Hophenmayer-Tokich and Krozer, 2008) and offer opportunities for them to be combined during stakeholder involvement.

One of the positive aspects of surveying and interviewing is the exceptional strategic effectiveness of acquisition of information concerning attitudes of individual stakeholders. By encouraging more complete and better explained responses, these strategies allow direct feedback from the respondent and give the interviewer the opportunity to gain more detailed information from each person. Moreover, through the interview, the respondent is likely to feel freer to express his or her opinion, mainly due to the lack of social control (Buchecker et al., 2010). Furthermore, the direct contact offers the opportunity to clarify questions, which in turn results in more detail and accuracy of data. Finally, surveys have the advantage that it is easier to include a larger proportion of the population and to assess more of it in detail. This form of communication allows the participants to bring in their values and viewpoints, but also their local knowledge (Hophenmayer-Tokich and Krozer, 2008). Thus, this approach can contribute to improving or adapting preventive strategies. Nonetheless, interviews still have some major drawbacks, with the main reason being that they do not reflect the power relationships among different stakeholders and they do not allow discussions and confrontation about specific problem issues. This can be a considerable limitation if the main objective of stakeholder involvement is the achievement of stakeholder consensus in a particular land or risk management decision (e.g. in the selection of the most suitable management measure to be adopted).

The involvement of stakeholders through a participatory process allows a higher level of stakeholder engagement, by giving participants the opportunity to communicate their views and judgments to the other participants, as well as learn from them. Participatory processes also enable participants to approach the problem in a more integrated way by encouraging exchanges of positions and considering issues in relation to the common good rather than individual interest. Additionally, participatory stakeholder involvement offers the opportunity to follow up with group dynamics in which evolving discussions play a key role. A core aspect of this approach is the way participants react to each other's responses and express their opinion: often as a reaction to what other participants have expressed. Hence, through participatory stakeholder involvement, participants can be challenged by others more profoundly than in semi-structured interviews. On the other hand, in participatory stakeholder involvement there is a tendency to avoid conflicts, in particular in cases where there is a certain familiarity and interdependence among the stakeholders (Parkins, 2010). Another shortcoming might be the limited number of participants that can be involved in participatory processes, and the limited availability of participants during the process that may have implications on the outcomes.

This school of thinking reflects that participation has stronger effects than surveys and interviews in empowering local stakeholders in land and risk decisions (HophenmayerTokich and Krozer, 2008). The participatory approach allows the active involvement of stakeholders to work hand-in-hand with land use planners and policy makers alike. Even though it is more difficult to engage stakeholders in active participation, the social effects are more comprehensive. It encourages stakeholder participation and creates realistic expectations via a networking of building trust. Involving stakeholders in the decision-making process facilitates the satisfaction of their needs (Wates, 1985; Sanoff, 1990; Towers, 1995; Al-Kodmany, 1999); moreover, active participation increases acceptance of decision-based planning (Luz, 2000, Bryner, 2001) and allows researchers and planners to access local expertise and knowledge (Roe, 2000), which, in turn, facilitates better decision-making all around. The main advantage of both approaches is that stakeholders' involvement is confirmed in the decision-making process through the collection of stakeholders preferences and the evaluation of their perception of risk. Both approaches, however, have their considerable weaknesses, and to overcome them, we suggest combining the two approaches. 


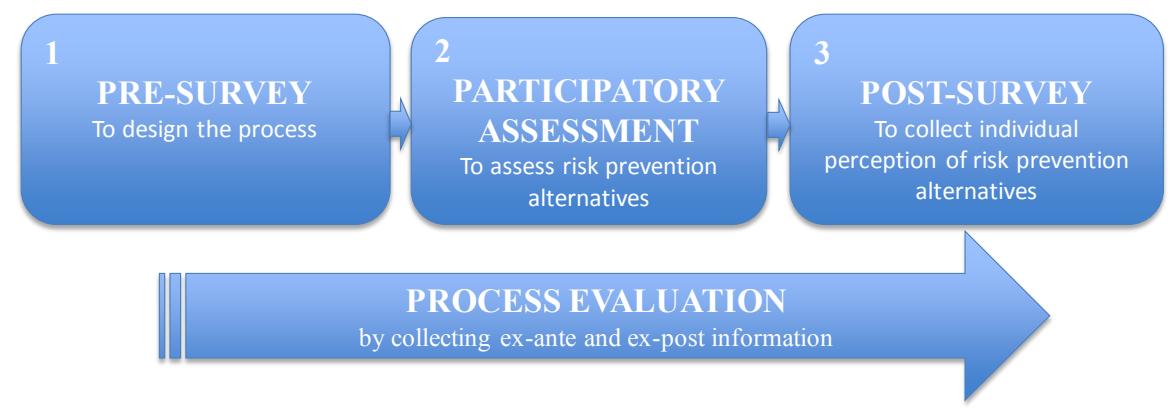

Fig. 1. Scheme of the proposed procedure.

\section{Proposed KULTURisk communication procedure to estimate risk perception}

As anticipated in Sect. 2, the development of a proposal within KULTURisk on how to capture risk perception to make flood risk management more effective was centered on the adoption of risk communication approaches.

Specifically, a risk communication procedure combining both one-way and two-way approaches (presented and discussed in Sect. 2.3), was developed. As depicted in Fig. 1, it is structured according to the following three steps:

1. a pre-survey: to design the process and to collect information on the ex ante situation;

2. a participatory assessment of risk prevention alternatives;

3. a post-survey: to collect individual perception of risk prevention alternatives and information on the ex post situation.

This is operationalized by handing out largely identical standardized questionnaires to the members of a stakeholders group: two or three weeks before and immediately after the participatory assessment (steps 1 and 3). The standardized questionnaire includes key items specific to stakeholders' knowledge regarding their assessments of risk prevention strategies, their trust in the authorities and experts, and their risk acceptance in terms of floods in the area of concern.

Between step 1 and 3, a participatory assessment is performed (step 2). In step 2, expert groups discuss their findings with a stakeholder group on the costs and benefits of possible prevention alternatives. Then, the stakeholder group has the task of assessing prevention alternatives (e.g. extending dikes) according to given criteria (e.g. protection effect, side effects for nature, agriculture, life quality and infrastructure, costs).

The proposed procedure offers not just the opportunity to combine the advantages of the consultative and the participatory approaches as described above, but the pre-survey can serve as a basis to optimally design the participatory process; the post-survey can serve as a tool to validate the outcome of the participatory process; and the repeated measurement (pre- and post-survey) is a method to record the dynamics of stakeholders' risk perception influenced by discursive risk communication and can serve to perform an evaluation of the process in order to learn from and improve it according to the concept of adaptive management (Cundill and Rodela, 2012).

The information gained in the pre-survey can, in particular, help to select the participants to be involved in the participatory process, to define the relevant criteria for evaluating the alternatives, to identify the conflicting issues, and to use that as a base to design the procedure of the participatory process (e.g. discussions in the plenum or in small groups).

The validation of the participatory process is mainly based on the comparison between the aggregated individual assessments of these prevention alternatives by the post-survey respondents and on the prioritization of the prevention alternatives as the outcome of the participatory process.

The process evaluation based on the comparison between the pre- and the post-survey does not only focus on the effect of discursive risk communication on risk perception, and on achieving a shared assessment of the prevention alternatives, but also considers the effects of the communication process on perceived uncertainties, accepted risk levels, and trust in the managing institutions.

The presented KULTURisk risk communication procedure was inspired, reflected, and further developed based on the evaluation of a participatory flood risk prevention assessment carried out on the Sihl River (Zurich, Switzerland). The participatory process and its evaluation were not conducted to test our procedure. This combined assessment exercise came about from a spontaneous collaboration between research and practice, and this experience formed a basis to further develop our idea. Accordingly, not all details of our case study correspond with the suggested procedure, such as the selection of the participants or the function of the pre-survey to inform the design of the participatory process. However, this assessment exercise allowed us to learn from the practice and to refine our proposal accordingly. The case of the participatory assessment of the Sihl River flood prevention is described and discussed in the following Sects. 4 and 5, as an illustrative example of the suggested procedure. 


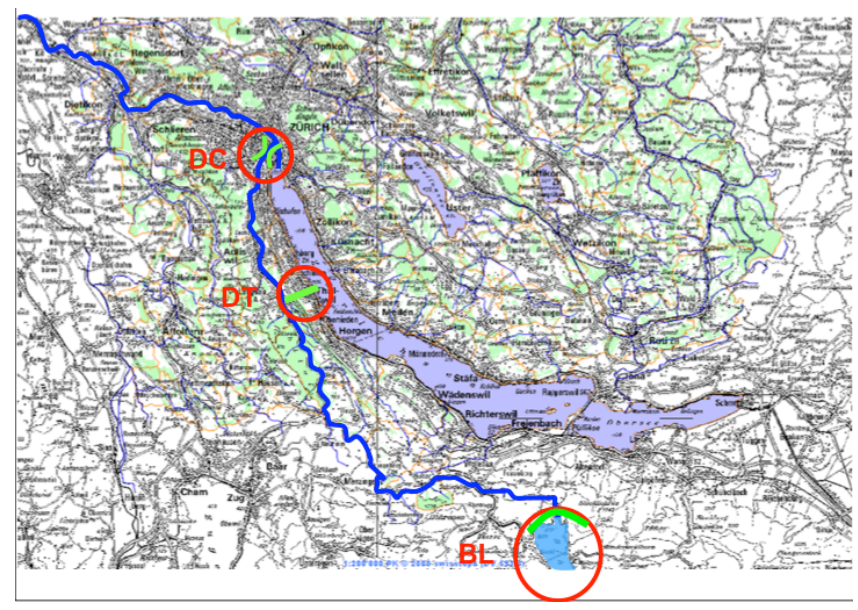

Fig. 2. The Sihl River basin and the locations of the three basic approaches for flood prevention of the Sihl: DC=extension of the discharge capacity of the Sihl Channel in Zürich; DT = discharge tunnel in the Zürich Lake; BL: lowering of the Sihl Barrier Lake.

\section{Participatory Sihl River flood prevention assessment}

\subsection{The study area}

The Sihl River is a pre-alpine river with a catchment area of $336 \mathrm{~km}^{2}$ that flows into Zurich, Switzerland and into the Limmat River (Fig. 2). Since 1938, the river discharge of the Sihl has been influenced by the presence of a reservoir located in the upper part of the river basin, namely the Sihl Barrier Lake, which is used for energy production. The Sihl River remains somewhat dangerous due to large parts of greater Zurich positioned alongside the alluvial cone of the river itself. During a flood event in 2005, the greater Zurich area barely escaped excessive damage by its inundations. It was simply due to fortune that the center of the rainfall was not within the drainage basin of the Sihl River.

Recent studies have revealed that the risk of a flood event occurring along the Sihl River is now slightly less than a HQ $100 \mathrm{yr}$ event, although, if triggered, this could easily bring about damage that surmounts CHF 5 billion. So the river represents one of the main observed flood related risks in Switzerland. The severity and need for action in terms of improving flood prevention recognises the requirement of preaction planning and implementation strategies. Besides immediate protection measures, including establishing an early warning system and improving the emergency planning processes, the idea is to incorporate long-term flood prevention in the Sihl River basin. Within this area there is a flood prevention project, led by the Cantonal Office for Waste, Water, Energy and Air (AWEL), that is conducted in collaboration with the City of Zurich, the Swiss Federal Railway (SBB), the Sihl Valley Uetliberg Railway, the cantonal building insurance companies and the affected municipalities, cantons and cantonal departments. This comprehensive project is a study on the possible solutions for sustainable flood protection for the Sihl River. AWEL mandated three teams of planners to investigate three basic approaches for flood prevention: (1) a discharge tunnel into the Zurich Lake; (2) an extension of the discharge capacity of the Sihl Channel in Zurich; and (3) a retention approach based around the lowering of the Sihl Barrier Lake and on early warning systems. The process followed by the flood prevention project is depicted in Fig. 3. A kick-off meeting was held in January 2011 with 46 participants, in which AWEL and the planning teams presented their solutions and informed the involved actors in detail about the general risk situation, the risk reduction potential, the necessary measures (associated with location, impacts and costs), and the remaining uncertainties. The elaborated solutions, or alternatives, were then assessed by an expert team with 6 members, and critically discussed and further developed in two additional workshops (held in June and September 2011) by an accompanying group (with 24 members) who represented a wider range of stakeholders (see Tables 2 and 3 for the list of participants and Fig. 4 for the organogram). Even though the accompanying group was mainly composed of governmental stakeholders, it covered a variety of administrative units at local, cantonal and federal level (see Sect. 5.2), and each of the participants represented a distinct perspective according to their professional background and the predominant rationales in their administrative units. During the assessment process, the 35 suggested solutions within the framework of the three original approaches (discharge, bypass, retention) were first condensed to 5 solution variants in Workshop 1, and then recombined in Workshop 2 to produce the final solution concepts: an optimised discharge tunnel and an optimised Sihl Lake (Fig. 3). Based on the results of this participatory assessment process, the Canton of Zurich will determine a strategy for a long-term flood prevention of the Sihl River that will serve as a basis for the political implementation of the prevention measures.

\subsection{Evaluation of the participatory assessment process on the flood prevention}

Two largely identical standardized questionnaires were handed out to the members of the stakeholder group immediately before and after the participatory assessment.

The standardized questionnaire included key items specific to stakeholders' knowledge regarding:

- multi-criteria assessments of the discussed solution alternatives for the flood prevention of the area of concern;

- perception of the flood risk;

- trust in the authorities and experts;

- risk acceptance in terms of floods in the area of concern; 
Table 2. Composition of the accompanying group.

\begin{tabular}{llr}
\hline Organization & Function & $\begin{array}{r}\text { Number of } \\
\text { representatives }\end{array}$ \\
\hline Federal administration & Risk prevention/Planning & 2 \\
\hline Federal Railway (SBB) & Management & 1 \\
\hline \multirow{2}{*}{ Cantonal administration Zürich } & Water management & 3 \\
& Water protection & 2 \\
& Lailding department & 3 \\
& Building insurance & 3 \\
Administration of other cantons & Planning and building & 1 \\
\hline \multirow{2}{*}{ City administration Zürich } & Engineering & 4 \\
& Waste management & 1 \\
\hline Other municipalities & Planning and landscape management & 3 \\
\hline
\end{tabular}

Table 3. Composition of the assessment team.

\begin{tabular}{llr}
\hline Organisation & Function & $\begin{array}{r}\text { Number of } \\
\text { representatives }\end{array}$ \\
\hline Cantonal administration & Building insurance & 1 \\
City administration & Engineering & 1 \\
Private companies & Engineering & 4 \\
\hline
\end{tabular}

- attitudes towards participatory flood management;

- assessed knowledge about the flood risk in the area of concern; and

- assessment of the participatory process.

The pre-measurement questionnaire was sent by mail to the members of the assessment group and of the accompanying group (30 people) shortly before the first workshop so there was insufficient time to use the results to inform the design of the participatory process. The questionnaire was completed by 20 of the participants who received it. During the first and second workshops, the posters on group discussions were documented and some discussions were recorded. The postmeasurement questionnaire was given to the participants of the final event of the assessment process (8 December 2011, Fig. 3) and additionally sent by email to all members of the assessment group and accompanying group. It was returned by 27 participants.

Due to the low sample size, a triangulation approach was applied to strengthen the validity of the results and to gain supplementary insights. Therefore, seven additional semistructured expert interviews were conducted with four members of the accompanying group, and one member from each of the planning teams. This approach was well suited for revealing underlying factors that influenced the participants' judgement. Since the responses to the standardized questionnaire indicated a high level of consensus among the participants, the interviews provided a source of information about the participants' detailed view, and how this view changed during the process.

\section{Results and discussion}

\subsection{Assessment of the participatory process}

Overall, the interviewees experienced the participatory process as an effective means of sustainable decision-making. Only one critical voice doubted that the broad involvement of stakeholders would result in a feasible solution. Others, who had been sceptical in this respect at the outset, lost their doubts during the process. All interviewees, and especially those who already had experience with involvement in participatory processes, highlighted the broadness of represented perspectives: even at an early stage of the decision-making. Some also experienced their involvement as personal enrichment. The following quotations illustrate how the participants assessed the participatory process:

RESPONDENT. In my view, the assessment process was special, because for the very first time I had the feeling that enormously broad participation was sought. Even peripheral fields were involved. ${ }^{1}$

RESPONDENT. It was exiting to learn about other people's views that emerge from completely different perspectives. Just to listen to them. It is interesting to have an opportunity to get to the heart of what is interesting for others, to know where the shoe pinches. ${ }^{2}$

\footnotetext{
${ }^{1}$ Officer of a cantonal building department; Aarau, 17 March 2012.

${ }^{2}$ Officer of the city's waste department; Zurich, 29 February 2012 .
} 


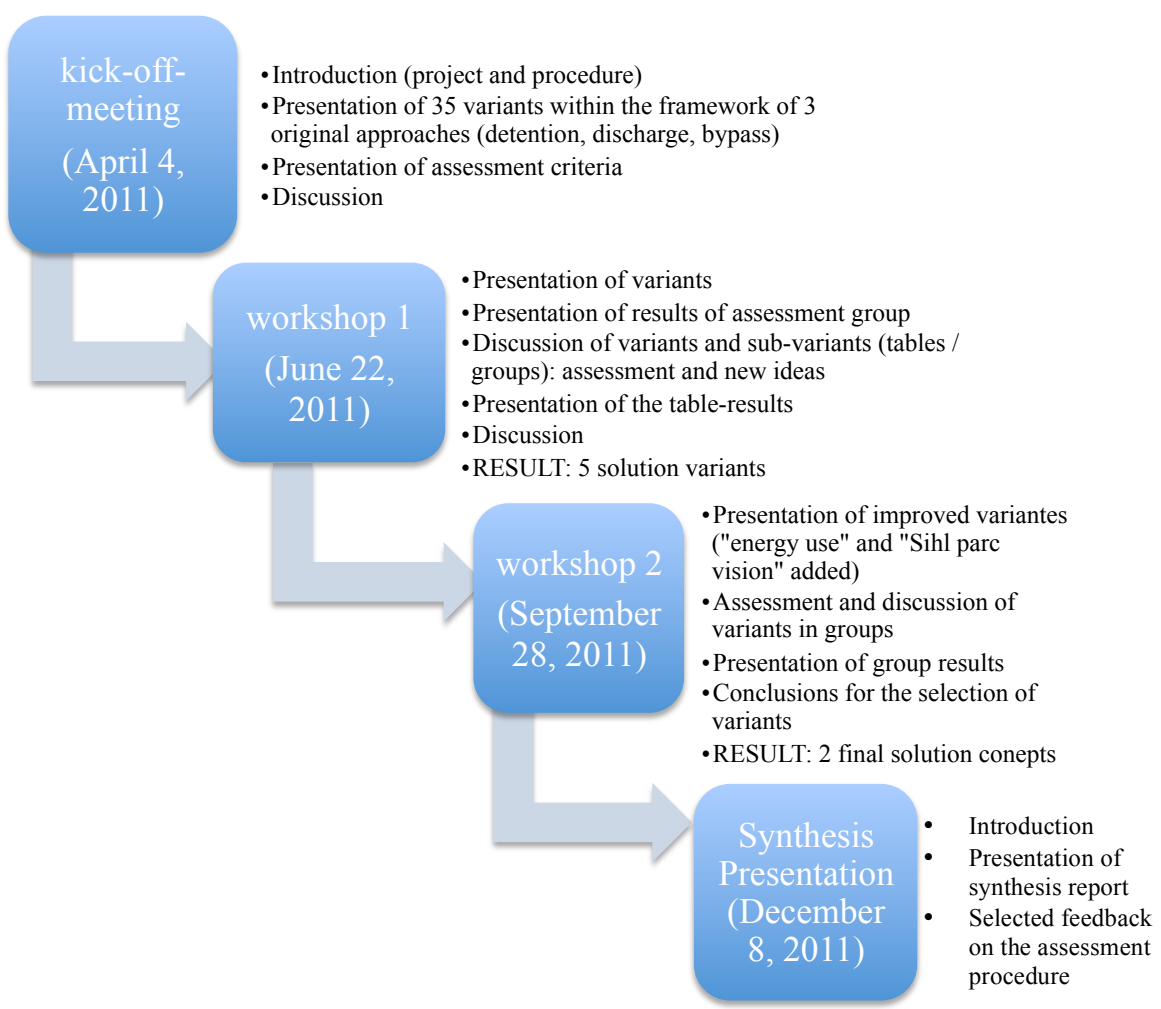

Fig. 3. Meetings and content of the process followed by the flood prevention project.

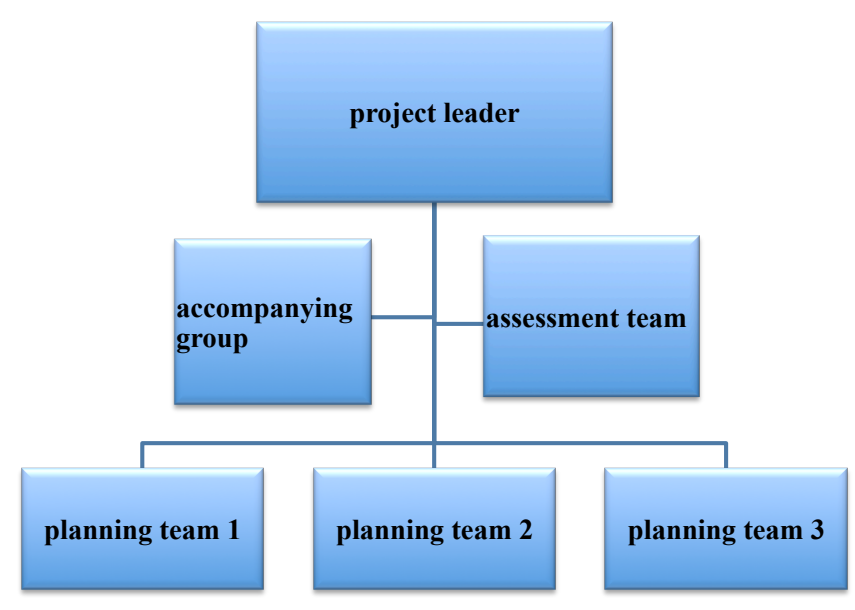

Fig. 4. Organigram of the flood prevention project. Source: Building Department of the Canton of Zurich, 2012.

It is striking that - with one exception - all interviewees evaluated the process very positively: both in terms of the quality of the outcome and in terms of personal enrichment. This raises the question of how participants develop such positive perceptions during the process. Possibly, they are inhibited by being unwilling to express oppositional opinions due to group dynamics, or to avoid conflict. It might be a subject of future research to examine the effect of participatory processes on the likelihood of expressing critical opinions.
In summary, it can be stated that involvement positively affected the participants' commitment to the process and thus guarantees a high acceptance of its outcome.

\subsection{Assessment of the variants}

The original variant of the discharge tunnel essentially remained the same during the experimentation process, so that a comparison of the assessments, before and after the assessment process, can be considered to mainly reflect a change in stakeholders' perceptions of this variant. The original variant of the Sihl Lake retention, however, was considerably modified by adding the idea of additional energy production, so the change of its assessment expresses a combination of a changed perception of the main retention idea and any additional benefits resulting from increased energy production or river restoration potential.

The three main changes that occurred during the evaluation process (Table 4) include: (1) the mean values of participants' overall assessments of the discharge tunnel variant decreased in absolute and relative terms (ranking); (2) the mean values of participants' assessments of the discharge tunnel variant increased in terms of all of the detailed criteria; and (3) the overall standard deviation of the tunnel variant decreased from 1 in $\mathrm{T} 1$ to 0.85 in $\mathrm{T} 2$, which indicates a consensus building among the participants. Remarkably, the favoured energy variant only performed better than the 
Table 4. Mean values of participants' assessments of the flood prevention variants of the Sihl according to 13 criteria before $(N=20)$ and after the assessment process $(N=25)$. Participants assessed the criteria on a 6-point scale ( $1=$ "fully insufficient" to $6=$ "very good").

\begin{tabular}{|c|c|c|c|c|c|}
\hline & \multicolumn{3}{|c|}{$\begin{array}{l}\text { Assessment before the process: } \\
\text { Original three variants }\end{array}$} & \multicolumn{2}{|c|}{$\begin{array}{l}\text { Assessment after the process: } \\
\text { Final solution concepts }\end{array}$} \\
\hline & $\begin{array}{r}\text { Discharge } \\
\text { tunnel }\end{array}$ & $\begin{array}{l}\text { Retention } \\
\text { Sihl Lake }\end{array}$ & $\begin{array}{l}\text { Discharge } \\
\text { capacity }\end{array}$ & $\begin{array}{r}\text { Optimised } \\
\text { discharge tunnel }\end{array}$ & $\begin{array}{r}\text { Optimised Sihl } \\
\text { Lake (Energy) }\end{array}$ \\
\hline Comprehensive belly feeling & 5.16 & 4.26 & 2.89 & 4.96 & 5.13 \\
\hline Protection against flood & 5.21 & 4.26 & 3.95 & 5.24 & 4.79 \\
\hline Control of overload & 4.72 & 4.00 & 3.61 & 4.83 & 4.42 \\
\hline Political implementation & 4.58 & 3.79 & 2.68 & 5.08 & 3.92 \\
\hline Technical implementation & 4.94 & 4.94 & 3.72 & 5.44 & 5.04 \\
\hline Consequences for the landscape & 4.63 & 4.00 & 2.84 & 5.00 & 4.56 \\
\hline Consequences for life quality & 4.83 & 4.16 & 3.32 & 5.21 & 4.61 \\
\hline Consequences for agriculture / forestry & 5.06 & 4.06 & 4.41 & & \\
\hline Consequences on infrastructural assets & 4.56 & 3.83 & 3.68 & 4.74 & 4.45 \\
\hline Consequences on nature protection & 4.44 & 3.83 & 3.61 & 4.76 & 4.12 \\
\hline Cost-effectivity in terms of investment & 4.25 & 5.00 & 3.94 & 4.44 & 5.24 \\
\hline Cost-effectivity in terms of servicing & 4.00 & 4.19 & 3.81 & 4.58 & 5.19 \\
\hline Cost-effectivity in terms of benefits & 4.13 & 4.53 & 3.93 & 4.42 & 5.65 \\
\hline
\end{tabular}

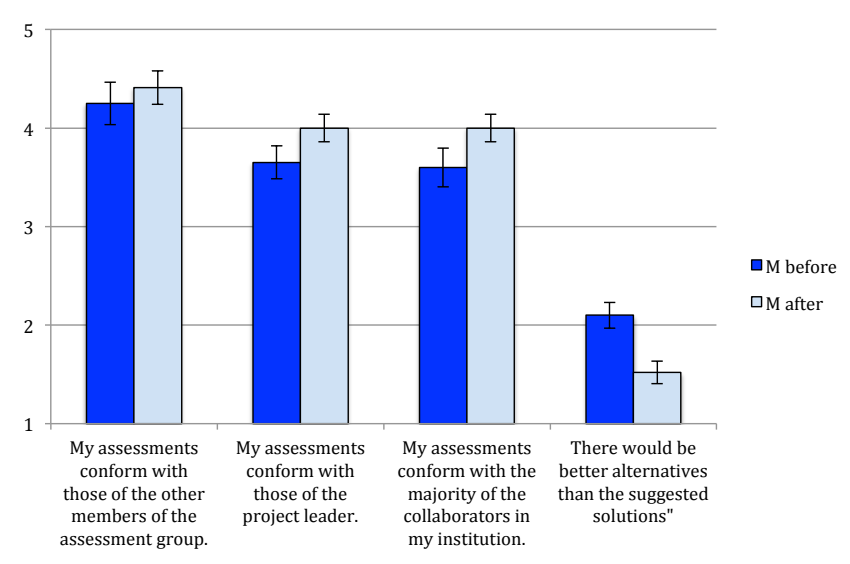

Fig. 5. The participants' perceived consensus before (T1) and after (T2) the assessment process.

discharge variant in terms of the cost-efficiency criteria. The additional energy benefits seem to be of high importance.

\subsection{Assessment of the achieved consensus}

In a domino effect, there seems to be an increased level of participant consensus in terms of the evaluation of the variants. Figure 5 illustrates the changes in the consensus among the participants that they perceived during the participatory process. Interestingly, the assessed consensus with the other members of the accompanying group and with AWEL, the leader of the flood prevention project, increased whereas consensus with the participants' own colleagues from their own institutions decreased. Consistent with these results is the belief that there were better alternatives than the options for which the discussion revealed a decreased consensus.
Expert interviews revealed how the process enhanced participants' consensus. With the exception of one interview partner who felt that he could not sufficiently bring his perspective into the assessment, all experts emphasized strong agreement with the resulting concepts. Getting into contact with participants with a different institutional and professional background opened up their minds to other perspectives and arguments: it especially provided the feeling that they could express their views as equals contributed to mutual understanding.

The exemplary quotation of one participant, which is in line with statements of other participants, illustrates how he became familiar with ideas that would have not been acceptable from the perspective of his institution:

RESPONDENT. The understanding for one or another variant that I would have - if I had not participated - maybe opposed, is now much, much better. So, now I can cotton on to variants - and I even can transport that to my organization, in which it was not considered a favourable variant. So, now (...) we can support the remaining variants very well. I think it is really a main benefit of the process getting across the understanding, and the knowledge, and also having the opportunity to shape the decision-making process and accompany the process.

It turned out that the participants initially tended to define their role in the process primarily as a representative of their own institution and they felt obliged to bring in that institution's perspective. During the process, they developed a sense of contributing to the superior objective of finding an optimal solution for the flood protection of the Sihl River.

However, in cases of strong commitment to a participant's own institution, and an initially dismissive attitude to the process, consensus could not always be reached. As another interview indicated: 


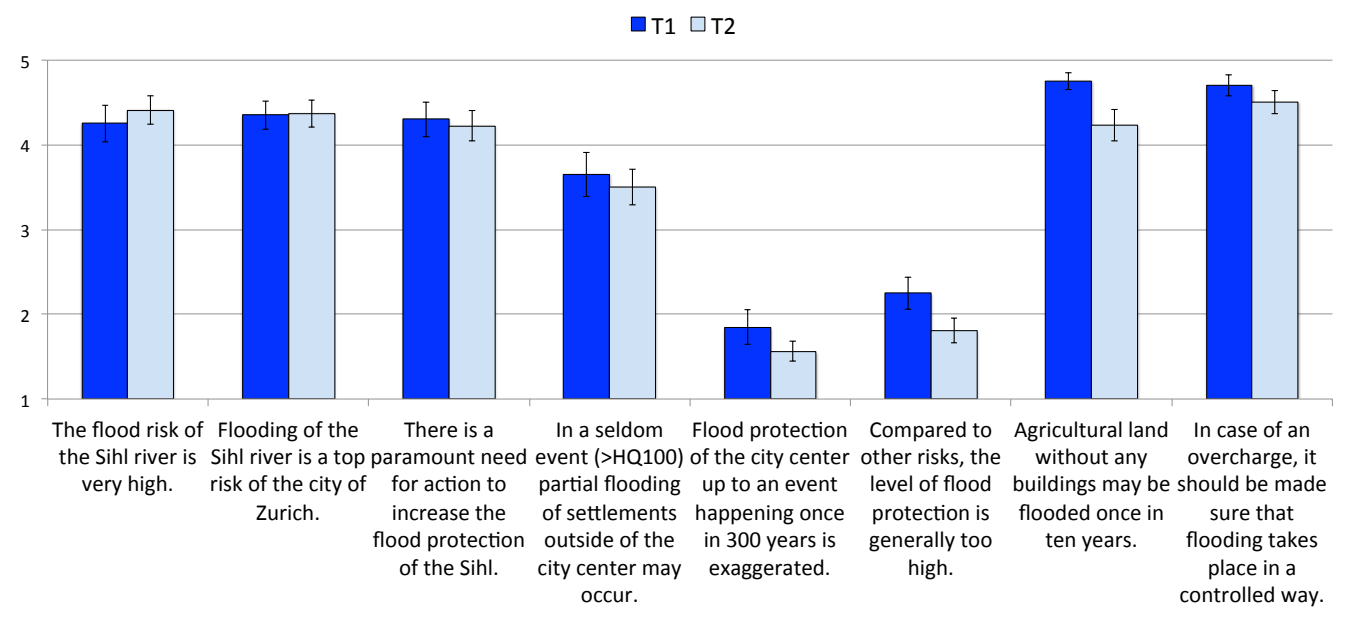

Fig. 6. Participants' risk perception before (T1) and after (T2) the participatory assessment process.

RESPONDENT. Actually, for us, for our department, it was really clear which project is the right one (...) Well, it is simply not thinkable to discharge the whole water through the city (laughing). But, of course, there are people concerned with environmental protection, and who knows what else. And they naturally think differently than real construction people, don't they?

\subsection{Effects on risk perception}

During the participatory assessment process, the perceived absolute flood risk (flood risk of the Sihl River) showed a slight increase while the perceived relative flood risk (top risk), as well as the need for action, marginally decreased (Fig. 6). This finding is possibly due to the euro crisis in that it may be assumed that the participants regard the need for action as less urgent, since the financial risk is more urgent than the flood risk. The level of flood risk awareness among the participants appeared to be already quite high at the stage before the participatory process. If these results would have been available at an earlier stage of the preparation of the participatory process, a possible feedback to the organisers could have been that the need for flood prevention was not a disputed issue and that therefore only little time in the workshop should have been dedicated to informing participants about the flood risk.

Much stronger effects could be observed in terms of participants' risk acceptance (Fig. 6) than in terms of risk perception. Consistent with the general discourse during the participatory assessment process; namely that potential damages within the greater Zurich area could drastically outweigh the prevention costs, participants' risk acceptance generally decreased. The only exception appeared to be the (increased) risk acceptance of uncontrolled overload, which is the case when a flood event goes beyond the capacities of the protection system.

\subsection{Effects on trust in the risk management}

In spite of the very positively evaluated quality of the participatory assessment process, trust in the cantonal expertise of AWEL was found to be high, and participants showed a high level of confidence in the AWEL's level of know-how. This illustrates the perceived quality of AWEL's flood risk communication (Fig. 7) and management competency in both risk management and floods.

The effect on trust in participatory risk management was confirmed by the expert interviews of which most evaluated the work of AWEL positively, and primarily the organisation of the process. Participants valued the consequent participatory approach at an early stage, the broad realm of expertise involved, and the effective organisation. Those participants who had already had experience with similar processes especially appreciated the quality of the organization.

RESPONDENT. I positively took note of how concentrated and well lead the process was. The risk of participation is that anybody can say anything without coordination and leadership. (...) Well, that is - there was an effective learning process, and that is what I really accredit to the circle around [the project leader] who had accompanied the [other process], knew it, and had drawn the right lessons from it. ${ }^{3}$

It is clear that AWEL's track record and ability to uphold a confident public perception of its aptitude within the region has put it at the forefront of coping with flood risk along the Sihl River. The participatory assessment process appears to have improved the perceived quality of the collaboration between the Canton and the City of Zurich.

\footnotetext{
${ }^{3}$ Officer of the building department of the canton of Zurich; Zurich, 15 March 2012.
} 


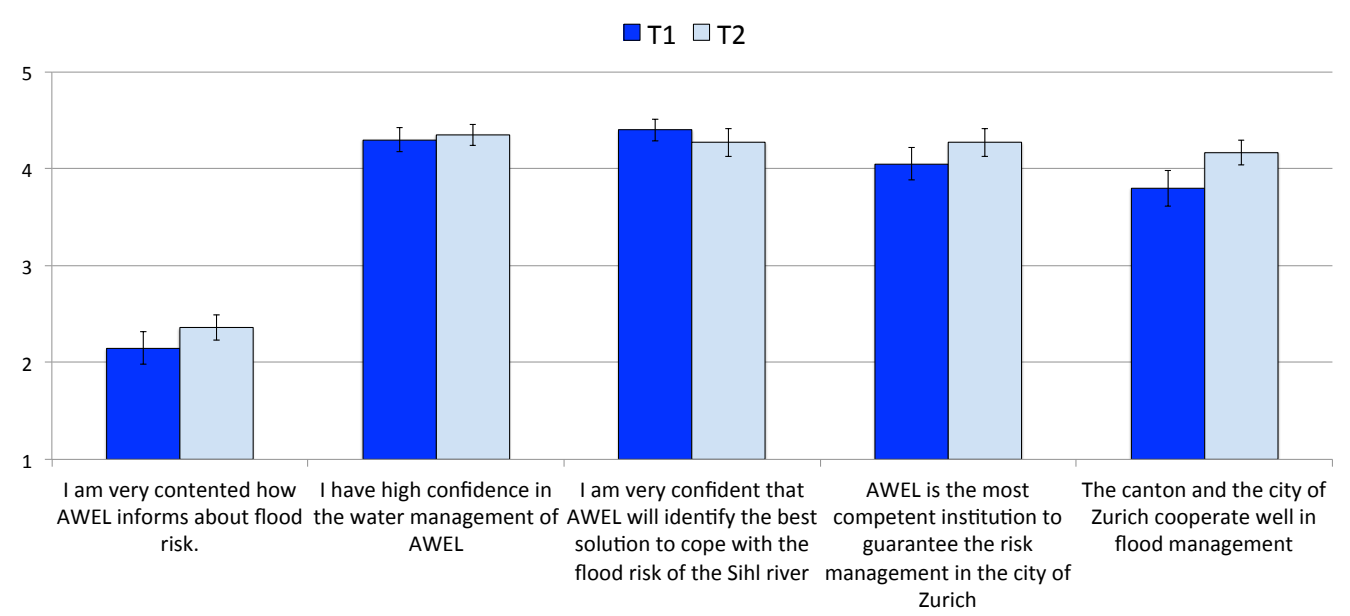

Fig. 7. Effects on trust in the risk management before (T1) and after (T2) the participatory assessment process.

\subsection{Limitations of the participatory flood assessment process and evaluation}

Most of the findings were not significant due to the low sample size and the even smaller number of respondents who participated in both surveys. However, the systematic trends of the survey results, together with the findings based on the interviews, are strong indicators that the participatory assessment process was successful in terms of consensus and trust building. In the overall evaluation of the process, participants expressed high levels of contentment with the outcome. They considered it to be worthwhile, both in terms of quality enhancement and in the relationship between effort and benefit. Most participants felt that they could bring in their own view and also revised their own perspective during the participatory process (Fig. 8).

Most interview partners agreed that this form of participation is exemplary for similar kinds of decision-making processes, such as for large projects with a wide scope of affected stakeholders. Otherwise the effort and expense would not be justified.

RESPONDENT. Of course, the effort needs to correspond to the scope of the project, or let's say the consequences of the project. (...) And then, the limitations, you have to regard that it won't get out of hand, don't you? That it is seized and structured clearly. (...) Another limitation is also - probably you can absorb a lot, but never cover all the arguments, ideas, opponents or alternatives. (...) Participation does not automatically help prevent objection. It is very likely that it reduces the probability of objections occurring and political opposition (...) but it does not eliminate it, does it? One must not have that illusion. ${ }^{4}$

\footnotetext{
${ }^{4}$ Engineer of a private company; Berne, 9 February 2012.
}

\section{Conclusions and further developments}

This paper aimed at providing an overview of the existing strategies to evaluate risk perception and at proposing a procedure to include risk perception in a risk assessment methodology for evaluating the benefits of water-related risk prevention.

A state of the art review on methods and approaches to evaluating risk perception and its dimensions (Sect. 2) allowed us to highlight that a gap between theory and practice in risk assessment and management exists. To bridge this gap, the findings of risk perception literature, being mainly of a theoretical nature, cannot provide sufficient detail to implement a comprehensive risk evaluation. In this context, two exceptions were mentioned: Modern Portfolio Theory (MPT) and its adaptation to natural hazards, namely Modern Disaster Theory; and the research carried out by Plattner et al. (2006b) on Perception Affecting Factors. Both MPT and PAF approaches allow a forecast of stakeholders' risk assessment, but they are highly individualistic and non-contextual because they do not consider the socio-cultural context of risk perception.

To incorporate the social aspects of the context into risk assessment, the inclusion of risk communication (both oneway and two-ways communication) is proposed in the KULTURisk risk communication procedure (Sect. 3) with the final aim of identifying the optimal risk prevention strategy, increasing the acceptance of the selected prevention measures, and thus making flood risk management more effective. The proposed procedure provides a practical suggestion for risk evaluation (as intended by Renn, 1998) which so far has not been implemented into practice. Moreover, its structure, composed of three steps, allows us to combine the risk assessment process with the evaluation of the process itself, which Höppner et al. (2012) point out is hardly ever achieved. 


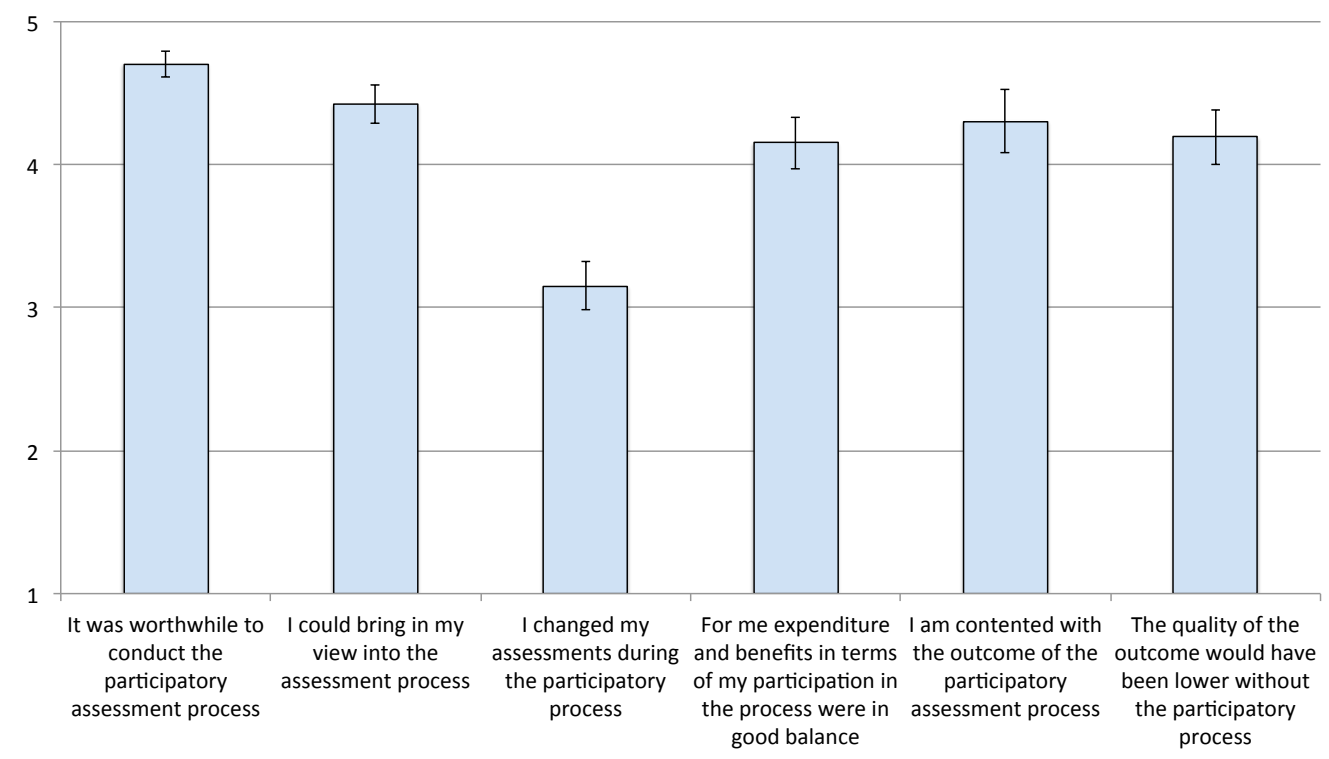

Fig. 8. Evaluation (T2, $N=25)$ after the participatory assessment process. Participants assessed the criteria on a 6-point scale $(1=$ "fully insufficient" to $6=$ "very sufficient").

An illustrative example of the proposed procedure (Sects. 4 and 5) allowed us to learn from the practice. The suggested procedure performed well in the Sihl River case study, and survey data contributed additional information for a better understanding of the participatory assessment process. It became clearer that the additional benefit of energy production was the key criterion, rather than flood protection characteristics, which made the participants prefer the combined lake retention alternative to the tunnel discharge alternative. However, it turned out that for future applications some adaptations of the procedure are needed.

In particular the one-way communication approaches (steps 1 and 3) need to be better integrated into the participatory process so that they can better fulfill their function and provide more reliable data. The first survey should be more explicitly announced as an input for the first workshop, which might also increase the participants' willingness to respond to it. Alternatively, the first survey could be conducted before the first information on the flood prevention alternatives is communicated so that the participants' problem perception could be better addressed in the participatory assessment process (Kolkman et al., 2007). The second survey should also be better integrated in the process and may be conducted as a final part of the synthesis workshop so that facilitators could ensure that all participants complete the questionnaire. Generally, more efforts are needed, in particular from the side of the organisers, to convince the participants of the added value of the two surveys for the whole process.

The one-way communication (steps 1 and 3) might be also conducted in the form of qualitative interviews and, if the number of participants is smaller than 20, this procedure should be selected as the main form of participant consultation. In this case, the sample of the repeated interviews should include members of all of the main stakeholder groups. Future scientific evaluations of such participatory assessment processes may furthermore include a control group of participants who only attend the information or synthesis workshops. This would allow for a more valid evaluation of the effects of the suggested procedure.

The next developmental steps will concern the integration of the proposed risk communication procedure into the KULTURisk risk assessment framework and methodology, which is currently under development. Specifically, the inclusion of a (semi) quantitative estimation of risk perception is foreseen as an indicator of adaptive capacity: to be integrated with both physical and environmental information and socioeconomic evaluation into a Multi Criteria Decision Analysis (MCDA)-based risk assessment methodology.

Acknowledgements. This work was found by the Seventh Framework Programme (FP7) of the European Commission within the collaborative project "Knowledge-based approach to develop a culture of risk prevention (KULTURisk)", FP7-ENV-2010, Project 265280; www.kulturisk.eu.

The authors thank two anonymous reviewers for their valuable suggestions for improving the manuscript.

Edited by: T. Glade

Reviewed by: three anonymous referees 


\section{References}

Aerts, J., Botzen, W. J. W., van der Veen, A., Krywkow, J., and Werners, S.: Dealing with uncertainty in flood management through diversification, Ecol. Soc., 13, available at: http://www. ecologyandsociety.org/vol13/iss1/art41/, 2008.

Al-Kodmany, K.: Using Visualization Techniques For Enhancing Public Participation, in: Planning And Design: Process, Implementation, And Evaluation, Landscape Urban Plan., 45, 37-45, 1999.

American Society for Civil Engineers, The New Orleans hurricane protection system: What Went Wrong and Why, Published by American Society of Civil Engineers, Reston, Virginia 20191, available at http://www.asce.org/uploadedFiles/Publications/ ASCE_News/2009/04_April/ERPreport.pdf, (last access: 5 October 2012), 2007.

Analysis, S. F. R.: Glossary of Risk Analysis Terms, available at: http://www.sra.org/resources_glossary.php (last access: 7 June 2005), 2005.

Ashley, R. M. and Blanksby, J.: Towards integrated approaches to increase resilience and robustness for the prevention adn mitigation of flood risk in urban areas, Advances in Urban Flood Management, London, Taylor and Francis, 415-432, 2007.

Belzer, R.: Getting beyond the grin and bear in the practice of risk management, Reliab. Eng. Syst. Safe., 72, 137-148, 2001.

Berkes, F., Colding, J., and Folke, C. (Eds.): Navigating SocialEcological Systems: Building Resilience for Complexity and Change, Cambridge University Press, Cambridge, UK, 2003.

Biggs, D., Abel, N., Knight, A. T., Leitch, A., Langston, A., and Ban, N. C.: The implementation crisis in conservation planning: could "mental models" help?, Conservation Letters, 4, 169-183, 2011.

Birkmann, J, Cardona, O. D., Carrenno, M. L., Barbat, A. H., Pelling, M., Schneiderbauer, S., Kienberger, S., Keiler, M., Alexander, D., Zeil, P., and Welle, T.: Framing vulnerability, risk and societal responses: the MOVE framework, Nat. Hazards, 67, 193-211, 2013.

Blöchl, A. and Braun, B.: Economic assessment of landslide risks in the Swabian Alb, Germany - research framework and first results of homeowners' and experts' surveys, Nat. Hazards Earth Syst. Sci., 5, 389-396, doi:10.5194/nhess-5-389-2005, 2005.

Blok, A.: Experts on public trial: on democratizing expertise through a Danish consensus conference, Public Underst. Sci., 16, 163-182, 2007.

Boholom, A.: Comparative studies of risk perception: a review of twenty years of research, J. Risk Res., 1, 135-163, 1998.

Bowman, L. and White, P.: "Community" perception of a disaster risk reduction intervention at Santa Ana (Ilamatepec) Vulcano, El Salvador, Environ. Hazards, 11, 138-154, 2012.

Brun, W.: Cognitive components in risk perception: natural vs. manmade risks, J. Behav. Decis. Making, 5, 117-132, 1992.

Bryner, G.: Cooperative instruments and policy making: assessing public participation in US Environmental regulation, Eur. Environ., 11, 49-60, 2001.

Bubeck, P., Botzen, W. J. W., Suu, L. T. T., and Aerts, J. C. J. H.: Do flood risk perceptions provide useful insights for flood risk management? Findings from Vietnam, J. Flood Risks Manage., 5, 295-302, 2012.
Buchecker, M., Meier, C., and Hunziker, M.: Measuring the effects of consensus-building processes with methods of intervention research, Eur. Plan. Stud., 18, 259-279, 2010.

Bundesamt für Umwelt, Wald und Landschaft: Risikoanalyse bei gravitativen Massenbewegungen, Umweltmaterialien, 107/1, Bern, 1999.

Burton, C. and Cutter, S. L.: Levee failures and social vulnerability in the Sacramento-San Joaquin Delta area, California, Nat. Hazards Rev., 9, 136-149, 2008.

Cirella, G. T., Semenzin, E., Critto, A., and Marcomini, A.: Natural Hazard Risk Assessment and Management Methodologies Review: Europe, in: Sustainable Cities and Military Installations, Springer Netherlands, 329-358, 2014.

Cousin, M. E., and Siegrist, M.: The public's knowledge of mobile communication and its influence on base station siting preferences, Health Risk Soc., 12, 231-250, 2010.

Crichton, D.: The Risk Triangle, in: Natural Disaster Management, edited by: Ingleton, J., Tudor Rose, London, 1999.

Cundill, G. and Rodela, R.: A review of assertions about the processes and outcomes of social learning in natural resource management, J. Environ. Manage., 113, 7-14, 2012.

Dake, K.: Orientating dispositions in the perceptions of risk: an analysis of contemporary worldviews and cultural biases, J. Cross Cult. Psychol., 22, 61-82, 1991.

Di Baldassarre, G. and Uhlenbrook, S.: Is the current flood of data enough? A treatise on research needs for the improvement of flood modelling, Hydrol. Process., 26, 153-158, 2012.

Di Baldassarre, G., Montanari, A., Lins, H., Koutsoyiannis, D., Brandimarte, L., and Bloeschl, G.: Flood fatalities in Africa: from diagnosis to mitigation, Geophys. Res. Lett., 37, L22402, doi:10.1029/2010GL045467, 2010.

Douglas, M.: Risk and Blame, Routledge, London, 1992.

Elton, E. J. and Grumer, M. J.: Modern Portfolio Theory, 1950 to Date, J. Banking and Fin., 21, 1743-1759, 1997.

European Commission: Directive 2007/60/EC of the European Parliament and of the Council of 23 October 2007 "on the assessment and management of flood risks", 2007.

Felt, U. and Wynne, B.: Taking European Knowledge Society Seriously, Report of the Expert Group on Science and Governance to the Science, Economy and Society Directorate, DirectorateGeneral for Research, European Commission, 2007.

Fiorino, D. J.: Citizen Participation and Environmental Risk - a Survey of Institutional Mechanisms, Sci. Technol. Hum. Val., 15, 226-243, 1990.

Fischhoff, B., Slovic, P., Lichtenstein, S., Read, S., and Combs, B.: How safe is safe enough? A psychometric study toward technological risks and benefits, Policy Sci., 9, 127-152, 1978.

Geiger, B. F.: A community case study to understand the school health education needs of adolescents for sexual risk reduction, Dissert. Abstr. Internat., 54, DA9409999, 1993.

Griesmeyer, J. M.: Risk aversion of the public or risk proneness of experts?, T. Am. Nucl. Soc., 41, 446-447, 1982.

Helm, P.: Integrated risk management for natural and technological disasters. Tephra, 15, 4-13, 1996.

Ho, M., Shaw, D., Shuyeu, L., and Yao-Chu, C.: How Do Disaster Characteristics Influence Risk Perception?, Risk Anal., 28, 635643, 2008.

Hollenstein, K.: Analyse, Bewertung und Management von Naturrisiken, Zürich, 1997. 
Hophmayer-Tokich, S. and Krozer, Y., Public participation in rural areas water management, Water International, 33, 1-15, 2008.

Höppner, C., Whittle, R., Bründl, M., and Buchecker, M.: Linking social capacities and risk communication in Europe: a gap between theory and practice?, Nat. Hazards, 64, 1753-1778, doi:10.1007/s11069-012-0356-5., 2012.

Howgate, O. R., Kenyon, W.: Community cooperation with natural flood management: a case study in the Scottish Borders, Area, 43, 329-340, 2009.

Jasanoff, S.: The political science of risk perception, Reliab. Eng. Syst. Safe., 59, 91-99, 1998.

Jurt Vicuña Muñoz, C.: Perceptions of Natural Hazards in the Context of Social, Cultural, Economic and Political Risks, A Case Study in South Tyrol. Diss, Birmensdorf, 2009.

Karger, C. and Wiedemann, P.: Kognitive und affektive Komponenten der Bewertung von Umweltrisiken, Zeitschrift für experimentelle Psychologie, 45, 334-344, 1998.

Kasperson, R. E., Renn, O., Slovic, P., Brown, H., Emel, J., Goble, R., Kasperson, J., and Ratick, S.: The Social Amplification of Risk: A Conceptual Framework, Risk Anal., 8, 177-187, 1988.

Kienholz, H.: Naturgefahren - Naturrisiken im Gebirge, Schweizerische Zeitschrift für Forstwesen, 145, 1-25, 1994.

Kienholz, H.: Naturgefahren und -risiken in Gebirgsräumen, in: Nachhaltigkeit als Leitbild der Umwelt- und Raumentwicklung in Europa, 51, Deutscher Geographentag, Stuttgart, 136-152, 1998.

Kolkman, M. J., van der Veen, A., and Geurts, P. A. T. M.: Controversies in Water Management: Frames and Mental Models, Environ. Impact Assess., 27, 685-706, 2007.

Lane, S. N., Odoni, N., Landstrom, C., Whatmore, S. J., Ward, N., and Bradley, S.: Doing flood risk science differently: an experiment in radical scientific method. Transactions of the Institute of British Geographers 36, 15-36, 2011.

Leighton, J. P. and Bisanz, G. L.: Children's and adults' knowledge and models of reasoning about the ozone layer and its depletion, Int. J. Sci. Education, 25, 117-139, 2003.

Lévy-Leboyer, C., Bonnes, M., Chase, J., Ferreira-Marques, J., and Pawlik, K.: Determinants of pro-environmental behaviors: a five-countries comparison, Eur. Psychol., 1, 123-129, doi:10.1027/1016-9040.1.2.123, 1996.

Ludy, J. and Kondolf, G. M.: Flood risk perception in lands "protected" by 100-year Levees, Nat. Hazards, 61, 829-842, 2012.

Luz, F.: Participatory landscape ecology-a basis for acceptance and implementation, Landsc. Urban Plann., 50, 157-166, 2000.

Marris, C., Langford, I., Saunderson, T., and O'Riordan, T.: Exploring the "psychometric paradigm": comparisons between aggregate and individual analyses, Risk Anal., 17, 303-312, 1997.

Merz, B. and Emmermann, R.: Dealing with Natural Hazards in Germany: From Reaction to Risk Management, GAIA 15/4, 265-274, 2006.

Merz, B., Hall, J., Disse, M., and Schumann, A.: Fluvial flood risk management in a changing world, Nat. Hazards Earth Syst. Sci., 10, 509-527, doi:10.5194/nhess-10-509-2010, 2010.

Milly, P. C. D., Wetherald, R. T., Dunne, K. A., and Delworth, T. L.: Increasing risk of great floods in a changing climate, Nature, 415, 514-517, 2002.

Morgan, M. G., Baruch Fischhoff, A. B., and Atman, C. J.: Risk communication: a mental models approach, Cambridge, Cambridge University Press, 2001.
Natan, F.: Risk perception, risk management and vulnerability to landslides in the hill slopes in the city of La Paz, Bolivia, A preliminary statement, Disasters, 32, 337-357, 2008.

Ohl, C. and Tapsell, S.: Flooding and human health: the dangers posed are not always obvious, Brit. Med. J., 321, 1167-1168, 2000.

Otway, H. J. and von Winterfeldt, D.: Beyond acceptable risk: on the social acceptabilities of technologies, Policy Sci., 14, 247256, 1982.

Parker, D. J. and Harding D. M.: Natural Hazard Evaluation, Perception and Adjustment, Geography, 64, 307-316, available at: http://www.jstor.org/stable/40569987, 1979.

Parkins, J. K.: The problem with trust: Insights from advisory committes in the forest sector, Soc. Natur. Resour., 23, 822-836, 2010.

Petrow, T., Thieken,A. H., Kreibich, H., Bahlburg, C. H., and Merz, B.: Improvements on Flood Alleviation in Germany: Lessons Learned from the Elbe Flood in August 2002, Environ. Manage., 38, 717-732, 2006.

Petts, J.: Public engagement to build trust: false hopes?, J. Risk Res., 11, 821-835, 2008.

Pidgeon, N.: Risk assessment, risk values and the social science programme: why do we need risk perception research, Reliab. Eng. Syst. Safe., 59, 5-15, 1998.

Pidgeon, N. F., Hood, C., Jones, D., and Turner, B. A.: Risk perception, in: Risk: Analysis, Perception and Management, The Royal Society, London, 89-134, 1992.

Plapp, T.: Wahrnehmung von Risiken aus Naturkatastrophen, Eine empirische Untersuchung in sechs gefaährdeten Gebieten Süd- und Westdeutschlands, vol. 2 of Karlsruher Reihe II: Risikoforschung und Versicherungsmanagement, Verlag für Versicherungswirtschaft, 2004.

Plattner, Th.: Evaluation of risks due to natural hazards. A conceptual approach, in: coping with risks due to natural hazards in the 21st Century, proceedings of the RISK 21 Workshop, edoted by: Ammann, J. W., Monte Verità, Ascona, Switzerlandm 28 November-3 December 2004, 67-76, 2006a.

Plattner, Th., Plapp, T., and Hebel, B.: Integrating public risk perception into formal natural hazard risk assessment, Nat. Hazards Earth Syst. Sci., 6, 471-483, doi:10.5194/nhess-6-471-2006, 2006b.

Posthumus, H., Hewett, C. J. M., and Morris, J.: Agricultural land use and flood risk management: Engaging with stakeholders in North Yorkshire, Agr. Water Manage., 95, 787-799, 2008.

Renn, O.: The role of risk perception for risk management, Reliab. Eng. Syst. Safe., 59, 49-62, 1998.

Renn, O.: White paper on risk governance: towards an integrative approach, International risk governance council, Geneva, 2005.

Roe, M.: Landscape planning for sustainability: community participation in estuary management plans, Landscape Res., 25, 157$181,2000$.

Rohrmann, B.: Risk Perception Research: Review and Documentation (Programme group men, environment, technology: studies on risk communication, Vol. 48) KFA Research Centre, Jülich, Germany, 1995

Rohrmann, B.: Risk perception research. Review and Documentation. Revised Edition, Research Center Juelich, Program group Man, Environment, Technology, Risk Communication Studies 69, Juelich, Germany, 1999. 
Rogers, R. W.: A protection motivation theory of fear appeals and attitude change, J. Psychol., 91, 93-114, 1975.

Saaty, T. L.: Decision Making with Dependence and Feedback: The Analytic Network Process, RWS Publications, Pittsburgh, PA, 2001.

Sanoff, H.: Participatory Design: Theory and Techniques, Bookmasters, Raleigh, NC, 1990.

Schmidt-Thomé, P., Greiving, S., Kallio, H., Leischhauer, M., and Jarva, J.: Economic risk maps of floods and earthquakes for European regions, Quaternary Int., 150, 103-112, 2006.

Siegrist, M. and Gutscher, H.: Flooding risks: A comparison of lay people's perceptions and expert's assessments in Switzerland, Risk Anal., 26, 983-991, 2006.

Sjöberg, L.: Factors in Risk Perception, Risk Anal., 20, 1-11, 2000.

Skjong, R. and Wentworth, B. H.: Expert judgement and risk perception, in: Offshore and polar engineering conference, ISOPE, vol. IV, 537-544, Stavanger, 2001.

Slovic, P.: Trust, emotion, sex, politics, and science: Surveying the risk-assessment battlefield, Risk Anal., 19, 689-701, 1999.

Slovic, P.: The perception of risk, Earthscan Publications, London, 2000.

Stirling, A.: Opening up or closing down: analysis, participation and power in the social appraisal of technology, in: Science and Citizens: Globalization and the Challenge of Engagement, Zed Books, London, 218-331, 2005.

Tansey, A.: Risk as politics, culture as power, J. Risk Res., 7, 17-31, 2004.
Towers, G.: Building Democracy: Community Architecture in the Inner City, University College London Press, London, 1995.

UNESCO: A world of Science, Natural Sciences Quarterly Newsletter, Unesco Publishing, Paris, France, 20 pp., 2004.

Vis, M., Klijn, F., De Bruijn, K. M., and Van Buuren, M.: Resilience strategies for flood risk management in the Netherlands, Int. J. River Basin Manag., 1, 33-44, 2003.

Vlek, C. J. H. and Stallen, P. J. M.: Rational and personal aspects of risk, Acta Psychol., 45, 273-300, 1980.

Vlek, C. J. H. and Stallen, P. J. M.: Judging risks and benefits in the small and in the large, Organ. Behav. Hum. Perf., 28, 235-271, 1981.

von Glasersfeld, E.: Questions and answers about radical constructivism, in: The practice of constructivism in science education, Lawrence Erlbaum Associates, Hillsdale, NJ, 23-38, 1993.

Wates, N.: Co-op consolidation, Architectural Rev., 177, 57-64, 1985.

White, G. F.: Human Adjustment to Floods, Department of Geography Research Paper no. 29, Chicago, The University of Chicago, 1945.

Wildavsky, A. and Dake, K.: Theories of risk perception: who fears what and why, Daedalus, 112, 41-50, 1990.

Wynne, B.: Public engagement as a means of restoring public trust in science - Hitting the notes, but missing the music?, Community Genet., 9, 211-220, 2006. 